\title{
Study on Survival Strategies of Farmers Engage in Small-Scale Household Cultivation of Edible Mushrooms: Take Shandong Province as an Example
}

\author{
Min Li, Jilian Hu \\ School of Economics and Management, Shandong Agriculture University, Tai'an, China \\ Email: limin1988@163.com, jlhu@sdau.edu.cn
}

Received 15 September 2014; revised 20 October 2014; accepted 6 November 2014

Copyright (C) 2014 by authors and Scientific Research Publishing Inc.

This work is licensed under the Creative Commons Attribution International License (CC BY). http://creativecommons.org/licenses/by/4.0/

\section{(c) (i) Open Access}

\begin{abstract}
Small-scale household production of edible mushrooms by farmers is the major source of edible mushrooms in China. However, large-scale enterprises who engage in commercial cultivation of edible mushrooms has been growing at a relatively fast pace, bringing about challenges for smallscale farmers. With the purpose of help maintain small-scale farmers' ability to survive in this fiercely competitive landscape, this paper first analyzes their competitive advantages, disadvantages and survival strategies, employing the methods of field survey and comparative observation. Based on these analyses, suggestions concerning how to strengthen the survivability of small-scale farmers are proposed, focusing on further lowering production cost and optimizing cooperative modes.
\end{abstract}

\section{Keywords}

Edible Mushrooms, Small Scale Household Production, Survivability, Survival Strategy

\section{Introduction}

Over the past few years, due to the sustained growth of demand and production of edible mushrooms, China has become the world's largest cultivator, consumer, and exporter of edible mushroom [1]. In 2003, the annual output of edible mushrooms of all kinds in China totaled 3148 tons, and the market value was over 207.6 billion 
CNY, with over 2 million people employed in edible mushroom industry. ${ }^{1}$ Edible mushrooms cultivation in China takes one of two basic forms; small-scale household cultivation by farmers; and large-scale commercial cultivation by enterprises. In the years 2011, 2012, 2013, the edible mushroom commercially cultivated by large-scale enterprises took up 3.85\%, 5.37\% and 6.51\%, respectively, of the total Chinese domestic output; with a balance of $96.15 \%, 94.63 \%$ and $93.49 \%$, respectively, cultivated by small-scale farmers. ${ }^{2}$ It can be concluded that the edible mushroom cultivation in China is dominated by small-scale farmers, who engage in household production of mushrooms (simply referred as "small-scale farmers" in this paper). Even though largescale enterprises have not become the major source of edible mushroom production, it has been growing at a very fast pace nationwide during the past few years, especially that of Shandong Province. According to surveys adopted by China Edible Mushroom Business website, the number of large-scale enterprises in Shandong Province has grown from 20 in 2010 to more than 120 in 2013. The rise of large-scale enterprises creates challenges for small-scale farmers. Based on our research in Shandong Province, it is found out that although small-scale farmers hold a competitive advantage due to the lower production costs and higher flexibility in production processes, when compared large-scale enterprises; they face numerous disadvantages, such as weak bargaining power, outdated production technology, high external transaction cost, relatively limited sales channels, along with a low risk-resistance capacity. In order to survive in this fiercely competitive landscape, small-scale farmers have, or tried to, employed the following three main survival strategies: competitive differentiation, cooperation, and product diversification. Based on these analyses, suggestions concerning how to strengthen the survivability of small-scale farmers were proposed in the end of this paper, focusing on further lowering cost of production and optimizing cooperation.

\section{Advantages of Small-Scale Farmers Compared with Large-Scale Enterprises}

\subsection{Small-Scale Farmers Enjoy Lower Production Cost}

\subsubsection{Cost of Fixed Assets}

Large-scale commercial cultivation of edible mushrooms requires significant initial investment of fixed assets. Enterprises generally are equipped with advanced mushroom growing infrastructure, with automated temperature, humidity and ventilation control systems; as well as support facilities such as R \& D laboratories, storage facilities with cooling systems; mass production facilities and lab equipment, etc. The large amount of capital outlay spent on fixed assets needs at least 5 years to recover, provided that the enterprise is enjoying a profit rate of $20 \%$. According to an investigation of 15 enterprises in Shandong Province, investment of fixed assets made up $66.7 \%$ - $75 \%$ of the enterprises total assets. Recovery of fixed assets investment takes a very long time.

In contrast, small-scale farmers usually build simple mushroom growing sheds or houses for edible mushroom cultivation; and purchase or rental of small agricultural machinery as needed. A survey conducted in Shandong province showed that the cost of building a simple mushroom growing shed is as low as 18 Chinese Yuan per square meter. Because of the advances and diversity of modern agricultural machinery, even small-scale farmers can achieve a level of mechanization, by using relatively small machinery specific to edible mushrooms cultivation in every step of the process. An investigation of factories manufacturing small agricultural machinery in Shandong Province (namely Zhangqiu, Qufu, Zhucheng and Zouping) showed that the lowest price of small machinery used in edible mushrooms cultivation ranges from 950 - 1200 Chinese Yuan, and is considered affordable for small-scale farmers.

\subsubsection{Cost of Labor}

Cultivation of edible mushrooms is highly labor-intensive. Constrained by the biological properties of edible mushrooms and machinery limitations, certain steps of the edible mushrooms cultivation process, such as picking and grading fresh mushrooms, rely completely on manual labor. As a result, large-scale enterprises face relatively high labor cost. To make things worse, as the cost of labor in China gradually rises, profit margin of most large-scale enterprises goes down.

For most small-scale farmers, it is family members of the household that participate in the actual cultivation

${ }^{1}$ Sources of cited figures: Edited data from China Edible Fungi Association website (http://www.cefa.org.cn/) and China Edible Mushroom Business website (http://www.mushroommarket.net/).

${ }^{2}$ Sources of cited figures: Edited data from China Edible Fungi Association website (http://www.cefa.org.cn/) and China Edible Mushroom Business website (http://www.mushroommarket.net/). 
process, and cost of labor is usually not calculated separately. For farmers with slightly larger scale of production, they tend to hire temporary laborers for the most labor intensive processes, such as mixing, sterilizing, and bagging the substrate, as well as harvesting. As such, the temporary labor cost constitutes a small percentage of the total production cost.

\subsubsection{Cost of Land}

Even though edible mushrooms cultivation does not require arable land, demand for land in general is at an all-time high, which is directly affecting the scale of production. Large-scale enterprises have to pay large fees and taxes to lease and use land. In addition, in order to build factories, or expand the scale of operation, enterprises have to bear additional transaction costs associated with this growth.

The cost of land for small-scale farmers is generally paid as a land-contracting fee set by local or national statutes, and it is generally significantly lower than the enterprises' cost of land. According to a survey conducted by Yang (2008) in 2008 for land use in Shandong Province, about 65\% of farmers in Shandong province use contracted land for free; while the other 35\% merely pay an average amount of 200 Chinese Yuan per year as land contracting fee [2]. With a relatively long history of implementing the household land contract system, most farmers have contracted land at their disposal, and can even lease other farmers' contracted land for a relatively small fee.

\subsubsection{Cost of Supervision and Motivation}

Workers in large-scale enterprises tend to have a low sense of responsibility. The cultivation process of edible mushrooms is intricate and requires a lot of direct labor input. Moreover, it is difficult to accurately measure the influence of individual workers on the final products, making it difficult to implement a rewards system to motivate employees. To improve the quality of work, enterprises generally intensify direct supervision, and/or motivate them financially, causing the cost of production to rise.

Small-scale farmers and their family members personally participate in production; they act not only as workers, but also as owner of the business. Quantity and quality of their work has a direct impact on the yield and quality of final products, and as such on their bottom line. Also family members are bound by non-financial connections, such as blood relation, as well as ethical and cultural obligations, which makes them more responsible for their behavior and more motivated to perform well. As a result, supervision and motivation is barely needed, and cost of supervision and motivation is relatively low.

\subsubsection{Cost of Labor}

Large-scale enterprises have more complex organizational structures, broader scope of business, and larger number of employees, resulting in high overhead costs, such as corporate management wages and benefits, office supplies, depreciation of office equipment, utilities, and insurance. According to the analysis of financial statements of a typical large-scale edible mushroom enterprise in Shandong province in fiscal year 2010-2013, administrative expenses account for $48.2 \%$ to $63.7 \%$ of period costs (see Table 1 ).

In contract, for small-scale farmers, it is family members who engage in edible mushroom production. There is no complex organizational structure or wide scope of business, resulting in low general and administrative expenses. In addition, due to the social characteristics of families, the administration process is simpler and more efficient, and various administrative expenses would generally not apply.

\subsection{Small-Scale Farmers Enjoy High Flexibility in Production}

\subsubsection{Flexibility in Entering and Exiting Market}

As mentioned earlier, large-scale enterprises generally require a large initial investment, making the barrier to

Table 1. Administrative expenses and period costs of a typical large-scale edible mushroom enterprise in Shandong Province in fiscal year 2010-2013 (Unit: Chinese Yuan).

\begin{tabular}{ccccc}
\hline & 2010 & 2011 & 2012 & 2013 \\
\hline Administrative Expenses & 2465163.48 & 4329998.30 & 5136971.14 & 9522636.51 \\
Period Costs & 4950146.62 & 6797128.75 & 10064060.99 & 19762103.09 \\
Ratio of Administrative Expenses to Period Costs & $49.80 \%$ & $63.70 \%$ & $51.04 \%$ & $48.19 \%$ \\
\hline
\end{tabular}

*Source: Financial Statements of Shandong Qihe Bio Technology Co., Ltd. 
market entry high. Based on a survey of 15 enterprises in Shandong Province, 13 of them had an initial investment of 50 million Chinese Yuan or more, while the other two had an initial investment of less than 10 million Chinese Yuan. In addition, enterprises' sunk costs are high, limiting their ability to freely exiting the market.

But for small-scale farmers, the entry barrier is relatively low. The initial investment, including the costs of building mushroom growing sheds and purchasing agricultural machinery, is bearable for most farmers. In practice, when the demand and prices are rising, some farmers even temporarily use facilities like their houses or vegetable growing sheds to cultivate edible mushrooms. Moreover, as a result of comparatively low sunk cost, it is easier for farmers to exit the market.

\subsubsection{Flexibility in Adjusting Scale of Production}

For large-scale enterprises, in order to increase output, large amount of fixed and variable costs per unit are needed. Similarly, if output is to be decreased, mushroom growing houses and equipment will not be fully utilized, causing great opportunity cost. Therefore, the scale of production cannot be adjusted frequently or rapidly.

By contrast, small-scale farmers' cost of production per unit and marginal costs change slightly with different scales of production, as compared with those of large-scale enterprises. In this sense, small-scale farmers can expand or reduce production flexibly, based on market demand and price.

\subsubsection{Flexibility in Changeover}

While large-scale enterprises enjoy economies of scale, they have to bear large amount of sunk costs, due to the high specificity of their fixed assets, such as mushroom growing houses, supporting facilities and production equipment. To shift production from one species of edible mushroom to another, certain growing houses and equipment will require costly modification in order to be utilized, and new technical workers will need to be trained. To switch to another agricultural produce, the cost of the changeover will be even higher. In other words, enterprises do not enjoy flexibility in changeover.

Production facilities, mainly referring to mushroom growing sheds or houses and production equipment, of small-scale framers have relatively low specificity. If other species of edible mushrooms or agricultural produce are to be cultivated, the changeover can be realized by simple upgrades or conversion of the growing sheds, such as removing shade or roofing material, or opening up more windows for ventilation purposes. Because of the high operability and low costs, changeover for small-scale farmers is relatively easy to achieve. In other words, farmers have high flexibility in product changeover.

\section{Factors Adversely Affecting Survivability of Small-Scale Farmers}

\subsection{Weak Bargaining Power}

\subsubsection{Price of Raw Materials}

Raw materials for edible mushroom production refers to materials used to make growing medium for mushroom cultivation, i.e. cotton seed hulls, corncobs, sawdust, cereal crops straw. Raw materials are the major cost of edible mushroom production, taking up $60 \%$ to $80 \%$ of total costs. However, the price of raw materials tends to fluctuate, thus affecting production cost and market price of edible mushroom. As edible mushroom have a higher price elasticity of demand than cereals, when market prices increase, demand for mushrooms decreases dramatically. Due to the limited production scale of small-scale farmers, their bargaining power with raw materials suppliers is weak. As a result, they are incapable of balancing out the effects of raw materials price fluctuations, giving rise to unstable income.

\subsubsection{Market Price of Edible Mushrooms}

The majority of edible mushroom producers are small-scale farmers with limited scale production. When these small-scale farmers sell fresh produce to agents or enterprises with selling contracts individually, as is mostly the case, they face fierce competition from other small-scale farmers and do not have pricing power. Consequently, they have to accept the price given by agents or enterprises, even if it is not a fair price. Weak bargaining power of small-scale farmers highly limits their earning ability.

\subsection{Outdated Production Technology and Unregulated Operations}

The process of edible mushroom production is complicated; it needs high level of technical knowledge of mu- 
shrooms, continuous monitoring, and timely manipulation of environmental conditions. To ensure product quality and improve efficiency; standard operations and advanced production technology are required. However, in real life, most small-scale farmers heavily rely on previous practical experience with mushroom cultivation, and operate casually; failing to obtain maximum yield or income. For instance, during the substrate treatment phase, if the substrate is not completely sterilized or not properly handled during transportation, it may become contaminated or infected. Also, during the fruit growing phase, maintaining appropriate temperature and humidity, in conjunction with active pest and disease control, are vital to mushroom production. Improper application of procedure during production will adversely affect the yield and quality of edible mushrooms, directly cutting into the farmer's bottom-line. Additionally, during the marketing phase, small-scale farmers persist in the use of outdated packaging, as well as poor transporting and storage techniques, making it hard to maintain the freshness and quality of mushrooms and maximize income.

\subsection{High External Transaction Costs}

External transaction costs for small-scale farmers are high. Small-scale farmers face high search and information costs due to their limited educational level and social connections. Small-scale farmers incur relatively high costs while searching for potential buyers and to gain access to accurate timely market information [3] [4]. Additionally, bargaining costs for farmers is high, as the most common sales channels for small-scale farmers are farmer's markets and wholesale markets, where price uncertainty and transaction frequency are high, and where competition with other small-scale farmers is fierce.

\subsection{Relatively Limited Sales Channels}

There are three main sales channels for small-scale farmers; selling edible mushroom produce at farmer's markets or wholesale markets, selling to brokers, and selling to contracting enterprises. However, most small-scale farmers do not have access to accurate market information, or complete understanding of sale channels operations. Additionally, their small production scale and weak bargaining position makes them unable to completely utilize all available sales channels [5], such as supermarkets, online sales, and overseas markets. Moreover, their use of outdated production technology, unregulated operation, and inadequate packaging and storage procedures causes the quality of mushroom to vary widely, crippling their ability to acquire maximum return on their investment.

\subsection{Low Capacity of Risk-Resistance}

Due to the short shelf life of fresh mushrooms and the difficulty in adjusting short term production scale, the cobweb model apply to the edible mushroom market [6]. As mentioned earlier, small-scale farmers' poor ability to search for and analyze information and data, results in lack of foresight when it comes to production scale adjustment in reaction to market demand and price fluctuations. Additionally, price elasticity of edible mushrooms is higher than that of the raw materials required in its cultivation, as such price fluctuations brings a higher market risk and more serious impact on small-scale farmers' earning ability. Coupled with their weak bargaining power, small-scale farmers' cannot balance out the risk that comes with price fluctuation.

\section{Survival Strategies Employed by Small-Scale Farmers}

\subsection{Competitive Differentiation Strategy}

The market segments of small-scale farmers and large-scale enterprises are not entirely overlapping. The specificities of cultivating some widely consumed mushroom varieties have limited their commercial cultivation by large-scale enterprises. As such, farmers can employ differentiation strategies, and widely cultivate these mushroom varieties.

Currently, the most common large-scale commercially cultivated mushroom species are Enokitake Mushrooms, Button Mushrooms, White Beech Mushrooms, King Oyster Mushrooms and Brown Clamshell Mushrooms (listed in Table 2). In contrast, mushrooms species that are not or cannot be widely commercially cultivated by large-scale enterprises, such as Grey Oyster Mushrooms, Wood Ear Mushrooms, Reishi Mushrooms and Shitake Mushrooms, are mainly cultivated by small-scale farmers. The fundamental reason why these 
Table 2. Top 5 large-scale commercially cultivated mushroom species and their daily output in 2013 (Unit: tons).

\begin{tabular}{cccc}
\hline Species & Daily Output & Species & Daily Output \\
\hline Enokitake Mushroom & 3666.64 & Brown Clamshell Mushroom & 237.1 \\
King Oyster Mushroom & 2107.82 & White Beech Mushroom & 225.23 \\
Button Mushroom & 447.63 & & \\
\hline
\end{tabular}

*Source: Edited data from China Edible Fungi Association website (http://www.cefa.org.cn/) and China Edible Mushroom Business website (http://www.mushroommarket.net/).

mushrooms cannot be cultivated commercially in large-scale is that, the ultimate goal for enterprises is to maximize profits; which makes some mushroom varieties economically unattractive to large-scale enterprises. For example, cultivation of certain mushroom varieties is capital intensive, requires a longer growing period, takes up too much space, requires complicated cultivation procedures, or bound by technical conditions limits their large-scale cultivation, all leading to a relatively low profit margin when contrasted with other more profitable varieties.

According to statistics from China Industry Information and China Edible Fungi Association's websites (see Figure 1), mushrooms that are not widely cultivated by large-scale enterprises took up 58.1\% of the total mushroom consumption in 2013, which leaves a relatively large market segment for small-scale farmers to survive and thrive. Additionally, the low cost of production for small-scale farmers, couple with the high demand and consumption trends, ensures reasonable profits for small-scale farmers.

\subsection{Cooperation Strategies}

In order to solve problems during the process of mushroom cultivation and marketing, some small-scale farmers form cooperative relationships. There are two main forms of cooperative relationships; one is the cooperation mode of "Farmers-Enterprises"; the other one is farmers' cooperatives [7].

Under the cooperation mode of "Farmers-Enterprises”, small-scale farmers and enterprises sign a selling contract, whereby farmers are responsible for cultivating mushrooms, while enterprises provide them with raw materials, premium mushroom strains, ready-to-use mushroom cultivation bags, and full technical support. Under this scheme, the enterprises buy the fresh produce from the small-scale farmers and market them through their own sales channels. This cooperation mode can effectively reduce transaction costs and lower the market risk for farmers, as well as cut cost of production for enterprises. Currently in Shandong province, this cooperation mode is widely adopted. One example is an enterprise in Qingdao entered a cooperation agreement with around 2000 small-scale farmers to cultivate Shitake Mushrooms, which led to an increase in the average annual income per square meter of over 30 Chinese Yuan. ${ }^{3}$

In contrast, by forming farmers' cooperatives, resources and supplies of individual farmers are aggregated, increasing the scale of raw material and mushroom produce transactions, and enhancing farmers' bargaining power. Moreover, cooperatives provide production technology support and accurate market information; help expand sales channels; lower market risk; and improve farmers' competitive strength; and increase their income. One example is a cooperative in Liaocheng with over 5000 members, and an average annual income per household of around 20,000 Chinese Yuan.

\subsection{Product Diversification Strategy}

To minimize risks and enhance earning ability, a large number of small-scale farmers, especially members of cooperatives, adopted the strategy of product diversification; which was made possible as a result of advances in mushroom strains research and development of cooperatives. Traditionally, cultivation requirements for most mushroom varieties made them impossible to cultivate during the hot summer months, without expensive cooling equipment. However, recent research advances resulted in the development of new mushroom varieties that are appropriate for cultivation in summer. Additionally, cooperatives allow individual farmers to share the cost and access to equipment that would otherwise be cost prohibitive for individual farmers. As such, it is now possible for small-scale farmers to cultivate mushrooms year-round.

\footnotetext{
${ }^{3}$ Source: iFeng.com (2013) Enterprises Promote Edible Mushroom Industry with Local Farmers in Jiaonan, Qingdao. (http://qd.ifeng.com/special/qdqyncp/detail_2013 04/25/747033 0.shtml).
} 


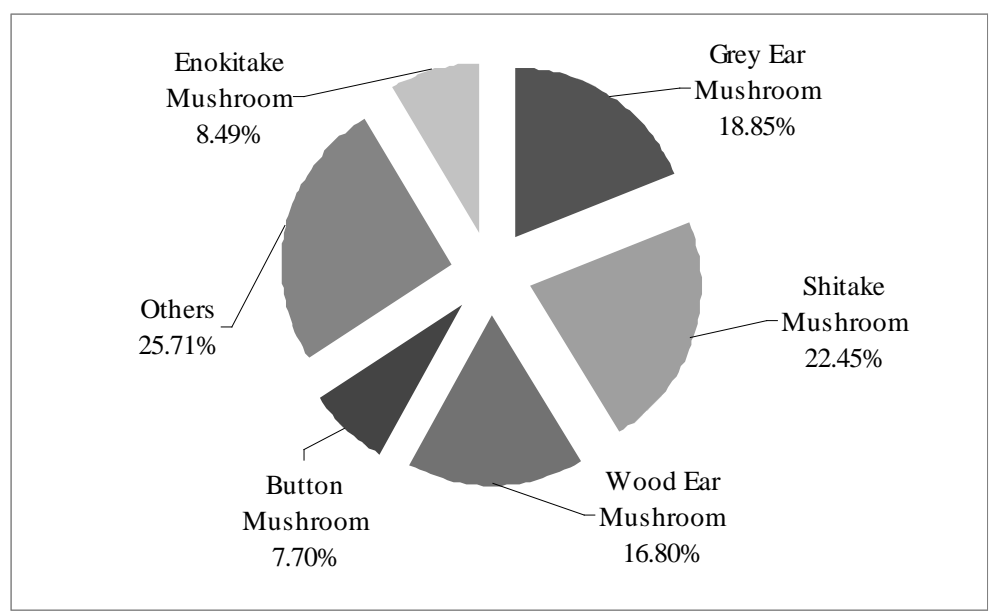

Figure 1. Mushroom consumption in China in the year 2013. * Source: Edited data from China Industry Information website (http://www.chyxx.com) and China Edible Fungi Association website (http://www.cefa.org.cn/).

Another difficulty preventing small-scale farmers from diversifying production is the lack of technical knowledge and guidance during the cultivation process. Cultivation of every mushroom variety comes with a fairly steep "learning curve" to become familiar with its unique culture mediums, and disease susceptibility. As such, technical guidance and support of operation techniques is of crucial importance to ensure peak production. Generally, cooperatives that employ diversification strategy offer technical guidance and support to its members. A local example is a cooperative from Tai'an that offers technical guidance and supports its members to allow them to diversify their production by growing Shitake Mushrooms during fall and winter, while growing Reishi Mushrooms during spring and summer, realizing year-round cultivation of mushrooms, significantly enhancing its member farmers' earning ability.

\section{Suggestions on How to Promote Small-Scale Farmers' Survivability}

\subsection{Further Lowering Production Costs}

Raw materials are the largest cost for mushroom production. However, market prices of raw materials heavily fluctuate, making it hard for small-scale farmers to control production costs [8]. As technology and research advances, the recycling of discarded and contaminated mushroom growing bags provides an effective way of lowering cost for raw material.

\subsubsection{Reuse Mushroom Growing Bags Disposed by Enterprises}

Each mushroom growing bag can be used for 3 to 5 cultivation batches. However, due to the reduction in yield after the first batches, most enterprises dispose the growing bags after the first batch. For example, for White Enokitake Mushroom, the yield from the second batch of a growing bag is reduced to $30 \%$ to $40 \%$ of the first batch [9] [10]. Due to enterprises' relatively high cost of production, the opportunity cost for growing second and later batches is high, and it is more economically feasible to only harvest the first batch of mushroom. Thus, enterprises generally discard the mushroom growing bags after one use or sell them at a very low price compared to the cost of a new growing bag. For small-scale farmers, the costs of production and daily operations are relatively low, even with low yield from the growing bags' second and later batches, it is still profitable to reuse these bags [10].

\subsubsection{Recycle Discarded Contaminated Mushroom Growing Bags}

During the mycelium growth period, $5 \%$ to $10 \%$ of the growing bags are contaminated, and are immediately discarded to prevent the spread of contamination. As the substrate within these growing bags still contains nutrition, after taking proper decontamination steps, including sterilization, fermentation, adding raw materials; they can be used for mushroom cultivation. The cost to purchase these contaminated growing bags can be as low as 
one tenth of the regular growing bags. And even considering the added cost of decontamination, the total cost of raw materials is still much lower than that of purchasing new mushroom growing bags, and can increase the farmer's profit margin. Small-scale farmers from other provinces in China have already adopted this strategy, and achieved measurable success. An example is a farmer from Anshan, Liaoning Province, who buys contaminated Shiitake mushroom growing bags from other growers, decontaminates them, processes the substrate, and makes them into new growing bags for Oyster mushroom, realizing a 50\% profit rate.

\subsection{Optimization of Cooperative Modes}

Although small-scale farmers' cooperation strategies have achieved some degree of success, there are issues during actual operations that call for optimization of the strategies. Under the simple cooperation mode of "Farmers-Enterprises", enterprises enjoy stronger bargaining power. By introducing cooperatives, which can effectively organize small-scale farmers, into this cooperation mode, the farmers will have more bargaining power in dealing with the enterprises. However, cooperatives are generally run by farmers, who lack professional, management, or operational skills and knowledge to be well organized or efficient, and as such fall short of their goals [11] [12]. This paper put forward the argument that cooperation mode of "Farmers-Bargaining Cooperatives-Enterprises" should be advocated in areas where the development of cooperatives is slow, and the cooperation mode of "Farmers-Cooperatives-Supermarkets" be adopted in areas where the development of cooperatives is advanced.

\subsubsection{Farmers-Bargaining Cooperatives-Enterprises}

Bargaining cooperatives are widely adopted by vegetable producers in the U.S. [13]. They are responsible for negotiating terms of contracts between small-scale farmers and enterprises, with the purpose of reducing the purchase price of raw materials and increasing the sale price of fresh produce [14] [15]. As mentioned earlier, the cost of raw materials takes up a majority of production costs; in this sense, bargaining cooperatives play an important role in reducing production cost for small-scale farmers. Additionally, cooperatives strive to help farmers get relatively high sale price for their product, as well as ensuring that enterprises fulfill their end of the bargain by clearly setting up terms of the contract, including payment methods and any conditions precedent, in writing. Bargaining cooperatives have a significant effect in helping farmers cut cost and increase earnings, while being relatively simple to set-up and manage. As such, it is suggested to promote the formation of bargaining cooperatives as a first step towards the development of fully functioning multi-purposes cooperatives.

\subsubsection{Farmers-Cooperatives-Supermarkets}

In developed countries, the supermarket is the main sales channel of agricultural produce. In China, as level of urbanization steadily rises, supermarkets have gradually become one of the main sales channels, especially in urban area. Forging alliances between farmers and supermarkets can reduce the cost associated with intermediaries in the distribution chain, and can improve the efficiency of the supply chain. Nevertheless, farmers are dispersed over large geological regions, the transaction cost for forming the required connections would be too high, plus the quality of the edible mushroom supply is hard to control. In contrast, cooperatives can overcome these obstacles by organizing these small-scale farmers; and by helping supermarkets monitor farmers to ensure a stable supply of quality mushrooms. Shi (2012) studied the cultivation and marketing of broccoli and came to the conclusion that, under the cooperation mode of "Farmers-Cooperatives-Supermarkets", logistics cost (cost of fuels, refrigerated storage, labor, etc.) saw a great decrease, while the quality of produce and farmers' earnings improved dramatically [16]. Within this cooperation mode, small-scale farmers can maintain stable sales channels and lower market risk. Additionally, edible mushroom distribution chain can be streamlined and extraneous intermediaries eliminated, lowering the transaction and logistics costs. Meanwhile, cooperatives and supermarkets can provide technological support and monitor small-scale farmers' work, improving productivity and the quality of mushrooms, and ensuring a steady supply of quality produce. This in turn can helps stabilize and raise market price for mushrooms, further increasing the farmers' earnings.

\section{Acknowledgements}

This work is supported by Shandong Agricultural Research System Fund (SDAIT-07-011-11). 


\section{References}

[1] Ge, Y.X. and Guo, Z.J. (2013) Comparison and Selection of Organization Modes in Edible Fungus Industry of Shandong Province. Asian Agricultural Research, 5, 33-37.

[2] Yang, X.C. (2008) Reflection of Rural Area Land Relationship-Based on Three Surveys Adopted in Shandong Province During 1995 and 2008. Management World, 7, 53-61.

[3] He, P.H. (2000) Research on the Significance and Measure to Lower Transaction Cost for Farmers. The World of Survey and Research, 7, 20-22.

[4] Hou, J.J. and Huo, X.X. (2013) Transaction Costs and Farmers' Choice of Marketing Channels in China - Empirical Evidence from Apple Planters of 124 Villages from 7 Provinces. Journal of Shanxi Finance and Economics University, 7, 56-64.

[5] Li, P., Wang, W.W. and Zhang, J.B. (2010) Analysis on Farmers' Cognition of Distribution from Economics Perspective-Take Edible Mushroom Growers as an Example. China Rural Survey, 6, 44-53, 65.

[6] Wang, C. (2009) The Contributing Factors, Influences and Improvement Measures of Chinese Agricultural Commodity Market Risk. Economic Review, 10, 72-75.

[7] Liu, W. (2012) Organization Modes of Edible Mushroom Industry in Anhui Province. Modern Agricultural Science and Technology, 21, 325, 327.

[8] Luo, X.F. and Jiang, S.Y. (2013) Study on Price Change Track OF Cotton Seed Hull and its Influence on Production of Edible Fungi-Analysis on Price Data of Cotton Seed Hull between 2010 and 2012 in China. Journal of Huazhong Agricultural University (Social Sciences Edition), 6, 59-64.

[9] Li, X. and LI, Y. (2014) Quality Comparison and Analysis on White Flammulina Velutipes Grown with Bottle Lines in China. Edible Fungi of China, 2, 20-24.

[10] Wang, X.Q. (2012) Recycle of Mushroom Stick Used for Manufacture of White Flammulina velutipes. Journal of Shanxi Agricultural Sciences, 6, 640-641, 660.

[11] Sun, H.Y. (2014) Analysis of Problems and Causes in the Development of Rural Cooperatives from the Market Perspective. Chinese Journal of Agricultural Resources and Regional Planning, 3, 140-144.

[12] Li, Y.P. (2013) Research on the Motivation Mechanism of Farmers' Specialized Cooperative Organization. Chinese Journal of Agricultural Resources and Regional Planning, 6, 205-209.

[13] Rehber, E. (2000) Vertical Coordination in the Agro-Food Industry and Contract Farming: A Comparative Study of Turkey and the USA (No.052). University of Connecticut, Department of Agricultural and Resource Economics, Charles J. Zwick Center for Food and Resource Policy.

[14] Siebert, J.B. (2001) The Role of Bargaining Cooperatives in a Global Market Economy. University of California, Center for Cooperatives.

[15] Marcus, G. (1994) Farm Bargaining Cooperatives: Group Action, Great Gain. United States Department of Agriculture.

[16] Shi, S., Wei, L.B. and Wu, J.Q. (2012) Cooperation Performance and its Surplus Allocation along Agri-food Supply Chain during "Farmer-Supermarket Direct Purchase"-Evidence from the Mode of "Farmer-Cooperative-Supermarket”. China Rural Survey, 4, 14-28. 
Scientific Research Publishing (SCIRP) is one of the largest Open Access journal publishers. It is currently publishing more than 200 open access, online, peer-reviewed journals covering a wide range of academic disciplines. SCIRP serves the worldwide academic communities and contributes to the progress and application of science with its publication.

Other selected journals from SCIRP are listed as below. Submit your manuscript to us via either submit@scirp.org or Online Submission Portal.
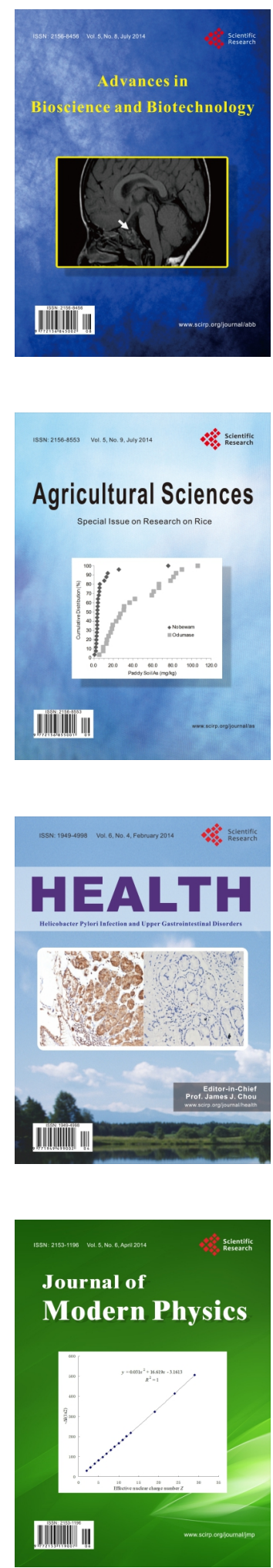
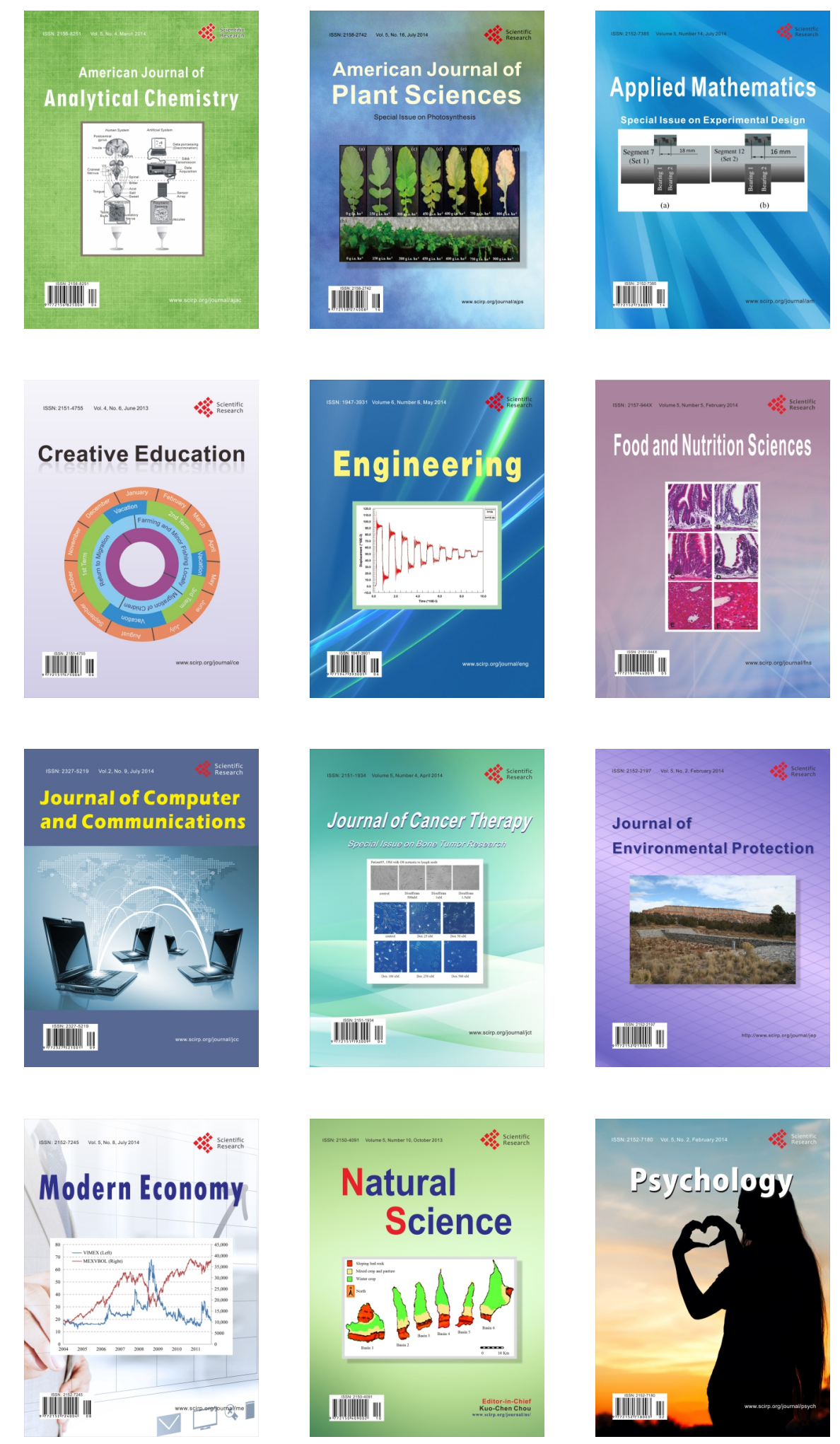